\title{
PANORAMA DO TRABALHO
}

\section{DOCENTE}

\author{
Jussara Bueno de Queiroz Paschoalino * \\ Maria Auxiliadora Monteiro Oliveira **
}

\section{RESUMO}

Este estudo faz parte de uma pesquisa maior de pó doutoramento. A análise aqui proposta neste artigo, s refere às análises conceptuais empreendidas a partir $c$ perspectivas que formam o mosaico do trabalho docente. Para descrever e refletir sobre o trabalho docente $r$ atualidade dois termos são utilizados com frequência para elucidar esta profissão que são: Identidade e perfil. Neste sentido este texto é resultado de uma pesquisa qualitativa, com a abordagem bibliográfica que analisou as produções sobre a temática em questão. As consultas foram realizadas ao Banco da CAPES, em que identificam o número de vezes, que alguns termos foram utilizados nas dissertações e teses, com o intuito de apresentar aspectos que direcionaram as reflexões da referida profissão. Os termos: Identidade docente e perfil docente foram analisados e constatados os seus devidos limites para expressar a dimensão do trabalho docente. As lacunas deixadas por estes dois termos para expressar a complexidade do trabalho docente possibilitaram a proposta pelo termo panorama, que amplia a perspectiva de compreender a dinamicidade e a dimensão metamorfoseada desta categoria profissional.

Palavras-chave: Trabalho docente. Identidade docente. Perfil docente. Panorama docente.

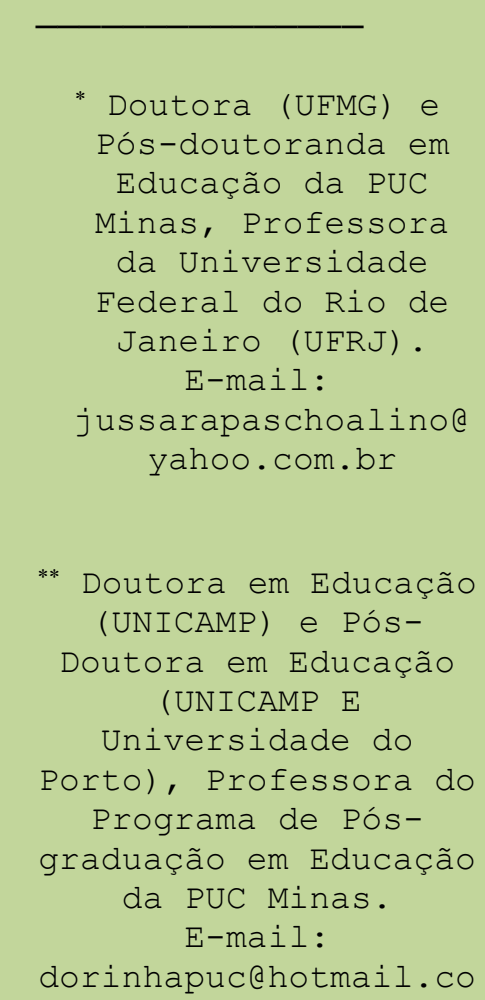

m 


\begin{abstract}
This study is part of a larger postdoctoral research. Th analysis proposed here in this communication refers to th conceptual analyzes undertaken from perspectives that for the mosaic of teaching work. To describe and reflect und current teaching work two terms are often used to elucidat this profession which are: Identity and profile. In this sens this text is the result of a qualitative research, with th bibliographical approach that analyzed the productions $\mathrm{c}$ the subject in question. The consultations were made to th CAPES Bank, in which they identify the number of times, thi some terms were used in dissertations and theses, in order to present aspects that guided the reflections of said profession. The terms: Teaching identity and teacher profile were analyzed and their due limits were verified to express the dimension of the teaching work. The gaps left by these two terms to express the complexity of the teaching work made possible the proposal by the term panorama, which broadens the perspective of understanding the dynamicity and the metamorphosed dimension of this professional category.
\end{abstract}

Keywords: Teaching work. Teaching identity. Teacher profile. Teaching perspective.

\title{
1 INTRODUÇÃO
}

Este estudo faz parte de uma pesquisa maior de pós-doutoramento. A análise aqui proposta, no artigo, se refere às análises conceptuais empreendidas a partir de perspectivas que formam o mosaico do trabalho docente. Para descrever e refletir sobre o trabalho docente na atualidade dois termos são utilizados com frequência para elucidar esta profissão que são: Identidade e perfil.

$\mathrm{Na}$ última década, a complexidade do trabalho docente e a peculiaridade e complexidade das relações que se conjecturaram na sua ação cotidiana têm levado à realização de pesquisas (GATTI, 2012; OLIVEIRA; BURNIER, 2013; OLIVEIRA; CUNHA; SOARES, 2015; PASCHOALINO, 2009; 2017; PASCHOALINO; ALTOÉ, 2015;

@rquivo Brasileiro de Educação, Belo Horizonte, v. 5, n. 12, set-dez, 2017. 
RAMOS, 2002; TARDIF; LESSARD, 2005; dentre outros).

Para adentrar no trabalho específico da docência, a opção neste artigo foi traçar a metodologia empregada e analisar os termos que possuem uma relevância ao se referirem ao trabalho docente, que foram: Identidade docente e perfil docente.

As considerações deste estudo proporcionaram a utilização de um terceiro termo: panorama para designar a profissão docente na sua dimensionalidade e que se metamorfoseia ao longo do tempo histórico, e assim, construir uma perspectiva analítica que retrate a dimensão complexa do da profissão professor.

\section{METODOLOGIA}

Este estudo buscou compreender como se retrata e designa a profissão nos tempos hodiernos. Neste sentido, foi escolhida a pesquisa qualitativa, a partir da abordagem bibliográfica que analisou as produções sobre a temática em questão.

As consultas foram realizadas ao Banco da Coordenação de Aperfeiçoamento de Pessoal de Nível Superior (CAPES), em que identificam o número de vezes, em que alguns termos foram utilizados nas dissertações e teses, com o intuito de apresentar aspectos que direcionaram as reflexões da referida profissão.

Vale salientar que, o Banco de Teses faz parte do Portal de Periódicos da CAPES/ Ministério da Educação (MEC), que possibilita a consulta da frequência de termos presentes nas dissertações e teses brasileiras desde 1987.

Nesta lógica, o Banco da Capes é organizado pelas “informações fornecidas diretamente à Capes pelos programas de pós-graduação, que se responsabilizam pela veracidade dos dados”. (CAPES, 2006). Esta produção organizada possibilita o uso de ferramentas diversas facilitando a consulta que pode ocorrer pelo autor, título e palavraschave.

Neste estudo foram realizadas as consultas dos termos analisados: Identidade docente e perfil docente durante o período de 1987 a 2016. E posteriormente a consulta de 
outro termo: Panorama docente, que escolhemos para designar a profissão no contexto atual.

\section{TRABALHO DOCENTE RETRATADO NAS PESQUISAS}

As frequências dos termos utilizados nas pesquisas marcam o entendimento do trabalho docente em determinado período. Nessa lógica, considera-se importante trazer, inicialmente, as escolhas teóricas que são utilizadas, muitas vezes como sinônimas, os termos identidade e perfil. São utilizados para se referir aos profissionais da educação, como, também, a vários outros grupos profissionais que se aproximam pelas suas características. Esses termos têm significados distintos na sua singularidade, como também na sua especificidade e as análises sobre eles permitiram estabelecer relações com o trabalho docente.

Com este entendimento o gráfico a seguir apresenta as frequências do termo: Identidade docente no período de 1987 a 2016.

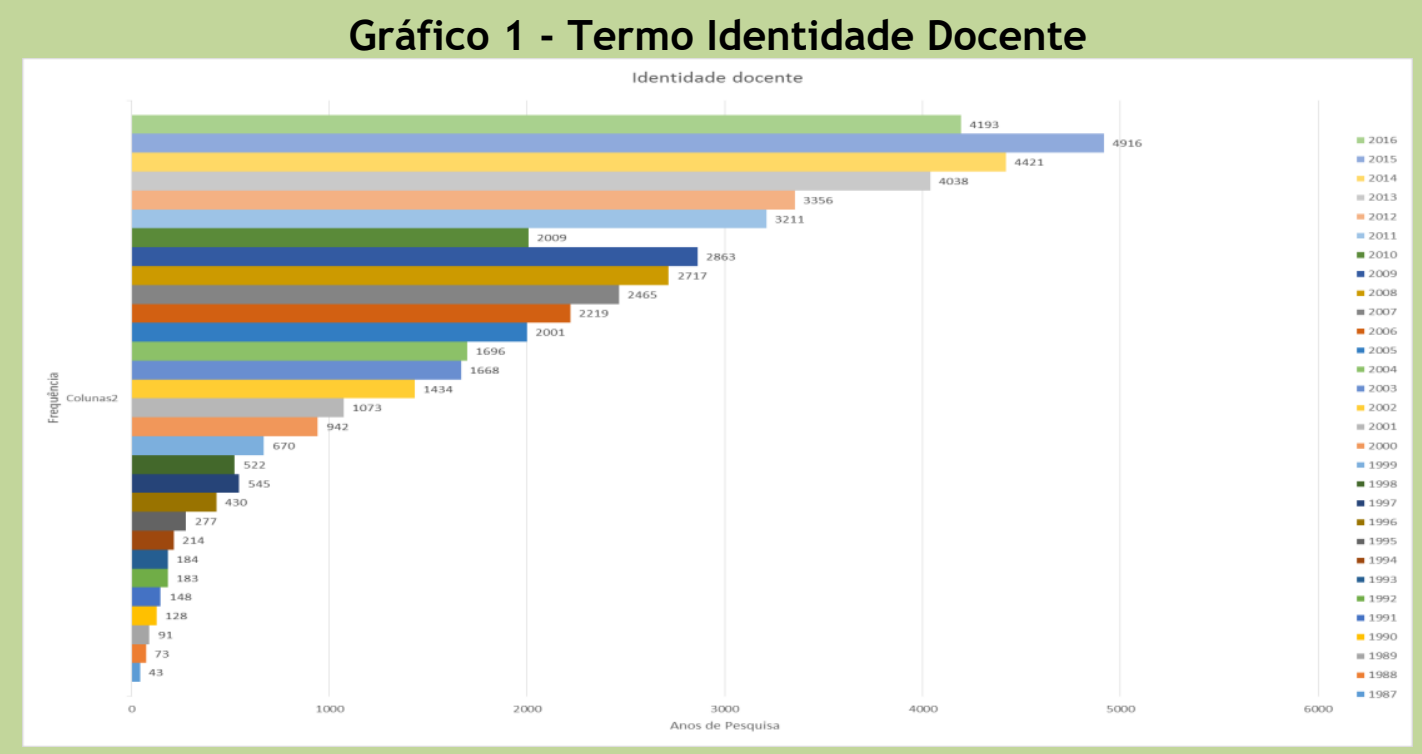

Fonte: CAPES/MEC

@rquivo Brasileiro de Educação, Belo Horizonte, v. 5, n. 12, set-dez, 2017. 
É nítido o crescimento deste termo nas pesquisas mais recentes conforme a análise do gráfico 1. Para o termo identidade docente foi obtida as frequências no total de 49.630 pelos resultados do Banco da Capes, que estavam presentes nas dissertações e teses.

De forma explícita, no período mais recente de 2012 a 2016 a frequência do termo: Identidade docente teve o crescimento considerável e foi possível constatar a frequência de resultados de 20.924 para o referido termo. Esta incidência permitiu refletir sobre a importância do mesmo para designar o trabalho docente.

Com o objetivo de aproximar-se do termo: Identidade docente buscou-se pelo seu significado e foi realizada primeiramente, a consulta ao Dicionário da Educação Profissional, em que trouxe a seguinte denominação: “[...] o termo identidade de significado abstrato, com raiz em "idêntico", entrou na linguagem filosófica como termo teórico" (CAMPOS, 2000, p. 30). No uso corrente, identidade é determinada pelo conhecimento e reconhecimento das características que assemelham determinado grupo e o diferencia dos demais.

A identidade profissional se delineia, nesta perspectiva: 0 termo identidade profissional caracteriza um processo de desenvolvimento psicossocial, em que se envolvem indivíduos e categorias profissionais (CAMPOS, 2000, p. 185).

As argumentações do autor mostram que o termo identidade transcende a dimensão profissional e se evidencia no processo psicossocial. Assim, vários aspectos interferem na dinâmica instaurada no processo educativo, principalmente, levando em conta os contextos: histórico, socioeconômico e cultural, de forma que a identidade emoldurada em aspectos restritos toma a conotação de crise e provoca a reflexão, que se traduz sobre o sujeito humano.

A crise de identidade que perpassa a sociedade "[...] é vista como parte de um processo mais amplo de mudança, que está deslocando as estruturas e processos centrais das sociedades modernas e abalando os quadros de referência que davam aos indivíduos uma ancoragem estável no mundo social." (HALL, 2001, p. 7).

Esse autor convoca a pensar a identidade como um processo construtivo, em sua essência humana, que está em constante processo de mudanças. Toda essa gama de 
relações e interações estabelecidas pelos humanos altera as chamadas identidades, que passam a ser voláteis e fluídas.

A identidade do professor também vem sendo abalada e vários aspectos salientam que não é possível compreender a docência da mesma forma; "a própria situação salarial dos docentes coloca a profissão e os seus profissionais em verdadeira crise, que abrange sua identidade e sua sobrevivência" (GATTI, 2012, p. 106).

Ao se referir à identidade do professor seria o mesmo que buscar alguns fios que tecem a complexidade do humano e perceber apenas similitudes, em detrimento de toda a trama existente. A tessitura é mais consistente e os fios desenham e redesenham as chamadas "identidades" dos professores.

Se a utilização do termo identidade, por si só, demandaria muitas reflexões que não seriam oportunas nesta análise, outro termo, perfil também ecoa um significado voltado para o campo de atuação do sujeito. Na conceitual de perfil pode ser definido como [...] conjunto de características, habilidades, aptidões, conhecimentos e interesses esperados de um trabalhador, tendo em vista uma determinada atividade profissional e o contexto social, tecnológico e cultural em que deverá atuar (MACHADO, 2000, p. 241).

0 termo perfil também apresentou frequência alta ao se referir ao trabalho docente. Pela pesquisa realizada no site do Banco de Dados da CAPES/MEC foi possível construir o gráfico abaixo com as frequências do uso do termo: Perfil docente. 
Gráfico 2 - Termo: perfil docente

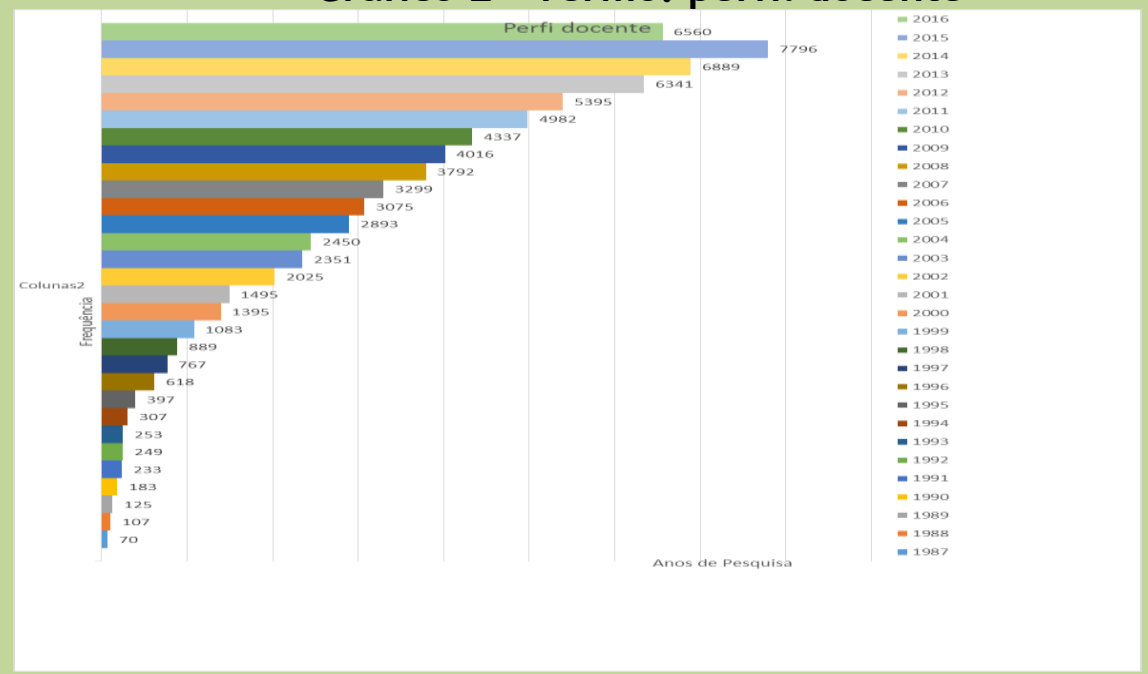

Fonte: CAPES/MEC

Desta forma, o termo perfil docente apresentou a frequência de 74.398 resultados durante o período de 1987 a 2016. Vale salientar que, no período mais recente de 2012 a 2016 obtive 32.985 resultados para perfil docente. Estes resultados permitem analisar como que o termo perfil docente teve acentuada presença nas pesquisas realizadas recentemente.

A compreensão do termo perfil docente também estabelece pontos de conflitos, ao pensar numa dimensão ampla da profissão.

[...] não se pode iludir a respeito do peso que têm nessas carreiras as singularidades da vida profissional em virtude da qual os docentes podem perfilhar diferentes pontos de vista sobre os atos de ensinar e aprender ou manifestar níveis de perseverança distintos no nível da concretização, em termos curriculares e pedagógicos, dos seus propósitos profissionais. É que sendo admissível pensar que essas conceções e suas implicações praxeológicas afetam o modo como um docente se perceciona, então será necessário valorizá-las no âmbito da reflexão sobre as vicissitudes, tensões e dilemas profissionais que atravessam a vida dos professores e contribuir, por essa via, para interpelar a natureza do trabalho que os professores pensam e realizam. (COSME; TRINDADE, 2017, p.565). 
Se por um lado, os aspectos curriculares e pedagógicos, dos seus propósitos profissionais interferem no perfil docente. Por outro lado, aspectos da singularidade do docente também predizem do seu perfil.

\begin{abstract}
Entende-se que a fragmentação dos modelos institucionais e a variação do perfil docente geram oportunidades e constrangimentos distintos, burilados pelos professores que constroem suas carreiras cotidianamente, com respostas que escapam aos padrões. Este artigo aponta a ocorrência de descentramento na produção do conhecimento, no conteúdo do profissionalismo, na fragmentação institucional e no perfil docente. (BONELLI, 2017, p.99).
\end{abstract}

Neste sentido, a autora supracitada elucida que questões relativas as dimensões: de fragmentação institucional, de gênero e de interseccionalidade também intervêm no perfil do docente.

A definição do termo perfil engloba aspectos essenciais que são referendados no campo profissional. Nesse sentido, os profissionais podem ser analisados e classificados dentro da dimensão do perfil, que abarca várias facetas do humano. Entretanto, ao final da análise dos termos identidade e perfil, a escolha recaiu sobre outro termo, ou seja, o panorama que ultrapassa os limites desses dois.

Vale salientar que, naturalmente, o uso desses termos pode levar a uma reflexão pertinente e apropriada de um grupo de profissionais, principalmente, pela multiplicidade de significados que são a eles acrescentados. Entretanto, a opção por outro termo não se estabelece apenas com uma simples mudança de palavra, mas tem por propósito se inscrever na perspectiva de estabelecer um elo com a discussão, que está sendo exposta, abrindo-se para a dimensão da complexidade do humano, especificamente, a complexidade do ser professor.

O estudo do trabalho docente se insere na complexidade de suas ações, ao compreender que o profissional professor convive com os dilemas decorrentes da sua escolha de atuação, nas múltiplas interações que realiza com os alunos, com seus pares, com a direção da escola, com a comunidade escolar, com o currículo estabelecido e com as leis educacionais (PASCHOALINO, 2009). É no seu dia a dia, no seu trabalho diário que o 
professor se forja nesse profissional da interação, sendo sua ação mediada pelos múltiplos aspectos do humano, agindo como um sujeito de ação e de modificação do contexto no qual está inserido. Nessa lógica da complexidade, o trabalho do docente se constitui como agente de mudança de forma explícita. Não se pode exercer a docência sem agir e interagir com toda uma gama de sentimentos, escolhas, decisões e, sobretudo, de ações (PASCHOALLINO, 2009). Todo esse emaranhado de interações questiona o professor na sua individualidade e, ao mesmo tempo, também no aspecto coletivo do exercício profissional.

$\mathrm{Na}$ perspectiva da complexidade, o docente tem a compreensão das suas muitas facetas profissionais, muitas imperceptíveis de imediato, mas que estão subscritas nas emoções e expressas em reações inesperadas. É nesse misto de interações diversas que o trabalho do professor pode ser denominado como uma profissão da incerteza, aspecto que pode até exigir um perfil para sua atuação. (TARDIF; LESSARD, 2005). No entanto, no exercício da profissão, o perfil do professor é alterado de forma significativa e constantemente. Assim sendo não se pode se referir a um perfil, mas de perfis variados que vão se alinhavando, no decorrer de sua atuação.

Nesta complexidade de tarefas e das relações, uma imposição tem tomado cena e contribuído com a culpabilização do trabalho docente, principalmente, nas ordens dos índices das provas externas colocam o professor num deslugar e numa situação de vulnerabilidade. (PASCHOALINO, 2017).

Em contraponto, a perspectiva de pensar um trabalho docente que seja valorizado e respeitado na abrangência do público e da qualidade.

Essa valorização no setor público - que sem dúvida passa pela remuneração condigna, mas também por outros aspectos relativos às condições de trabalho - tornou-se lema, uma vez que tem seus impactos na qualidade da educação escolar ofertada nas redes públicas de ensino. A questão é como materializar esse lema. Não resta dúvida de que o país não pode mais postergar o aumento dos investimentos nos sistemas de educação pública e na melhoria das condições de trabalho, de carreira e de remuneração de seus professores. A emergência, nas sociedades contemporâneas, das necessidades de reconhecimento social e do senso de injustiça estendem a problemática da valorização dos professores da educação básica para além das questões remuneratórias, embora estas sejam parte importante nesse processo. (GATTI, 2012, p. 109).

@rquivo Brasileiro de Educação, Belo Horizonte, v. 5, n. 12, set-dez, 2017. 
Se esses aspectos redesenham a complexidade de ser professor em um campo amplo, também, em um campo micro de articulação de cada unidade escolar se forja o clima organizacional que favorece ou dificulta o ser professor.

Outra dimensão essencial do trabalho docente situa na formação do mesmo que deve acompanhar as descobertas cientificas e se pautar em novas tecnologias.

\begin{abstract}
No contexto atual, caracterizado pelo extraordinário avanço técnicocientifico, faz-se cada vez mais necessário que os professores dessa modalidade de educação sejam formados, de modo mais amplo e aprofundado, nos campos teóricos, prático e didático-pedagógico, para que eles possam contribuir para a constituição de uma força laboral sintonizada com os requerimentos atuais da sociedade e do mundo do trabalho, atuando no exercício do magistério de forma autônoma, criativa, solidária, ética e crítica. (OLIVEIRA; CUNHA; SOARES, 2015, p.57).
\end{abstract}

A perspectiva abordada pelas autoras ultrapassa a formação acadêmica indispensável para a atuação no trabalho docente. E, assim, apresenta as outras conjugações que determinam a formação com a dimensão de integralidade de ser humano, que deve ser pautado pela ética, criatividade, solidariedade e criticidade. Corroborando com este pensamento de formação que rompe com as barreiras estabelecidas e se compromete com uma:

[...] educação tratada como um direito inegociável e que se opõe às formas de privatizações da escola. Ou seja, educação como uma prática social que pode colaborar e se compromete com processos de transformação estrutural da formação social brasileira, e objetiva formar sujeitos autônomos, cidadãos lúcidos, críticos e propositivos nos âmbitos individual e coletivo (OLIVEIRA; BURNIER, 2013, p.135).

Toda esta cobrança do fazer docente se acrescenta a outras demandas da atualidade. Nos novos requerimentos o trabalho docente também configura nas dimensões de habilidades e competências.

@rquivo Brasileiro de Educação, Belo Horizonte, v. 5, n. 12, set-dez, 2017. 
No contexto dessas transformações, estudos sociológicos e pedagógicos recuperam o debate sobre a qualificação, ao mesmo tempo em que se testemunha a emergência da noção de competência atendendo a, pelo menos, dois propósitos: a) reordenar conceitualmente a compreensão da relação trabalho/educação, desviando o foco dos empregos, das ocupações e das tarefas para o trabalhador, em suas implicações subjetivas com o trabalho; b) institucionalizar novas formas de educar/formar os trabalhadores e gerir internamente às organizações e no mercado de trabalho em geral, sob novos códigos profissionais. (RAMOS, 2002, p. 401).

Para entender o trabalho docente é importante buscarmos compreender as relações humanas com os meios e as normas presentes no trabalho. Neste sentido, para Canguilhem, (2001) a vida humana é demarcada por normas que tentam regular a sua ação.

Numa reflexão sobre o trabalho na perspectiva do modelo taylorista, no qual se espera uma execução precisa de acordo com as prescrições estabelecidas pelas normas antecedentes Canguilhem, (2001) afirma que a norma prescrita determina que certo trabalho deva ser realizado por um único método aceitável. Nesse sentido, a tentativa era de:

[...] mecanizar o homem e de mecanizar o tempo, negligenciando sistematicamente o caráter rítmico de atividade de um ser vivo qualquer, pode-se estabelecer a norma de rendimento de um determinado operário pela medida do tempo mínimo praticado por diferentes operários para cada elemento de uma tarefa decomposta. O inconveniente é esta norma não ter nenhuma significação concreta para um indivíduo tomado em sua totalidade bio-psicológica de sua existência. (CANGUILHEM, 2001, p.118).

Para o autor não é possível uma única norma, como não há uma única racionalização, mas uma pluralidade de racionalizações. Essa pluralidade de racionalizações se deve aos valores, pois todo homem deseja ser sujeito de suas próprias normas. Para o autor, o homem age no seu meio de trabalho construindo sua normatividade, que é o próprio sentido da vida. O sentido da vida opera como mediador entre:

[...] o mecânico e o valor, é dela (a vida) que se tiram por abstração, como termos de um conflito sempre aberto, e por isto mesmo gerador de toda experiência e de toda história, o mecanismo e o valor. 0 trabalho é a 
forma que toma para o homem o esforço universal de solução do conflito. (CANGUILHEM, 2001, p.120-121).

O autor supracitado nos fala que as normas do trabalho estão no aspecto mecânico, "mas só são normas pela sua relação com a polaridade axiológica da vida, da qual a humanidade é a tomada de consciência" (CANGUILHEM, 2001, p. 121). Dessa forma, só é possível entender a norma do social para o vital, a partir da sociedade nas quais as normas e as definições de normalidade são construídas. Entendendo que norma ou regra é aquilo que serve para endireitar, buscamos o sentido do que seria o normal.

Canguilhem (2002) afirma que o termo normal se naturalizou na França a partir do século XIX, em duas instituições: a instituição pedagógica, para designar um protótipo escolar e a instituição sanitária, para designar um estado de saúde orgânica. Assim, a escola normal é considerada a escola onde se ensina a ensinar através de instituírem experimentalmente métodos pedagógicos. A normalização dos meios técnicos de educação deve ser entendida como:

[...] expressão de exigências coletivas cujo conjunto define, em determinada sociedade histórica, seu modo de relacionar sua estrutura, ou talvez suas estruturas, com aquilo que ela considera como sendo seu bem particular, mesmo que não haja uma tomada de consciência por parte dos indivíduos. (CANGUILHEM, 2002, p.210-211).

O conceito de norma é polêmico, pois traz embutido em si o sentido de aversão a algo existente no social. Só se busca uma norma para que haja correção de infrações. Assim, as normas estão acompanhadas de sua contradição, que se traduz na própria existência do humano.

O ser humano diante de seu trabalho o recria constantemente, podendo até estabelecer uma sinergia entre os trabalhadores, formando coletivos na execução de uma atividade. A atividade industriosa não se limita ao exercício da tarefa tal como foi planejada, pois ao se empenhar na sua execução o ser humano coloca a si mesmo, recriando-a. 
Dessa maneira, nessas diferentes formas de inserção nas situações de trabalho o trabalhador recria, faz micro escolhas para gerir a sua própria ação, não necessariamente mais libertadoras e mais emancipatórias. Evidentemente que isso depende da história desse coletivo de trabalhadores.

Schwartz (1996) constata que as atividades humanas são permeadas por valores que norteiam as renormalizações no trabalho e na própria vida. Os valores para esse autor estão em dois âmbitos diferentes, sendo um deles pautado pelos valores mercantis e noutro polo os valores sem dimensão, entre eles o bem comum, a justiça e a cultura. Com esta lógica, o trabalho docente se insere no polo dos valores sem dimensão e, portanto, trazem na sua especificidade a complexidade das relações.

Diante de todas essas considerações, a escolha do termo panorama pareceu-me o mais apropriado. "Termo criado com o prefixo grego pan "todos" e da palavra grega horama 'view', derivado do Horan 'ver', foi usado em Inglês com a sua atual direção desde o início do século XIX ." (SOCA, s/d).

Com este entendimento, as tessituras do fazer e do constituir-se dos professores foram apresentando um panorama abstruso e multifacetado, de trajetórias distintas. Nessa lógica, a análise realizada permitiu constatar que cada instituição educacional constrói um panorama, marcado pela complexidade, pois as pessoas que convivem nesse espaço, também, carregam a carga implexa de sua própria existência.

@rquivo Brasileiro de Educação, Belo Horizonte, v. 5, n. 12, set-dez, 2017. 


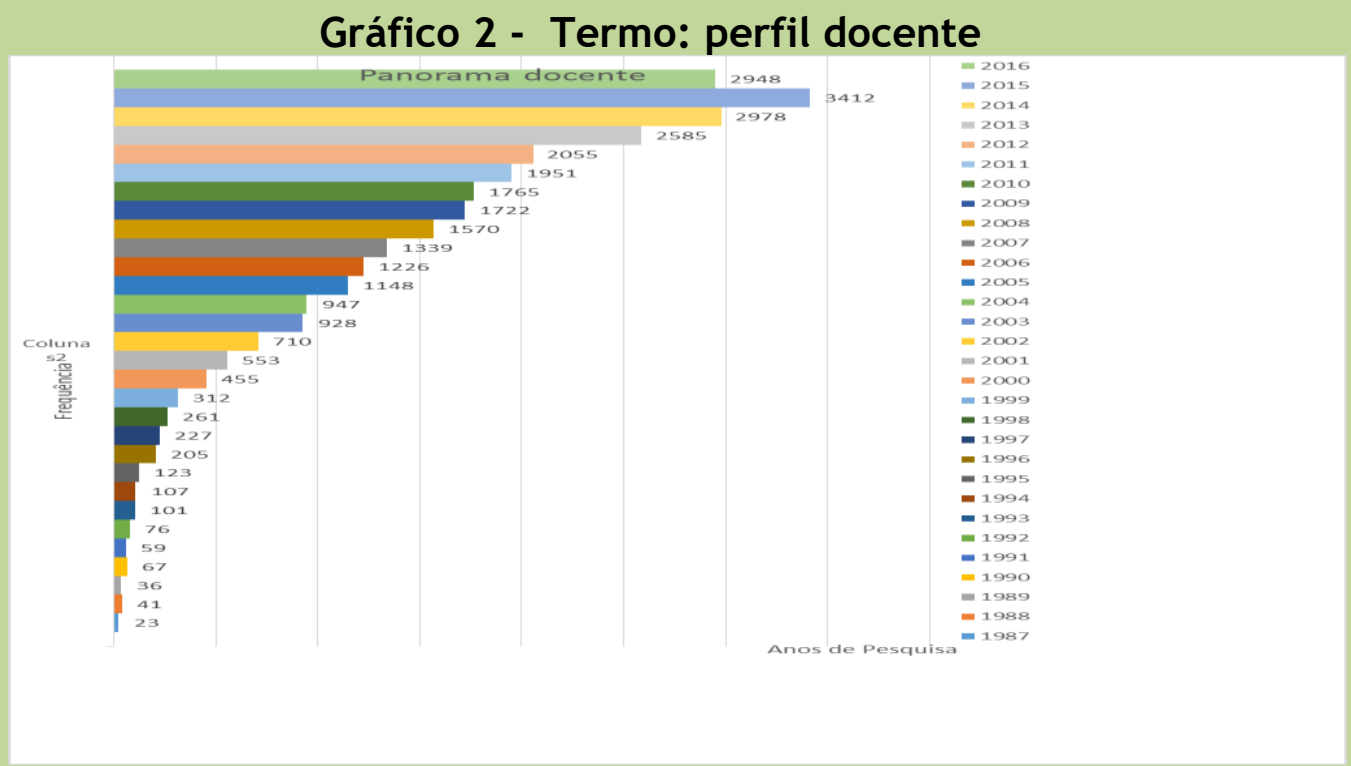

Fonte: CAPES/MEC

Na pesquisa realizada no Banco de Dados da CAPES/MEC foi encontrado o número de 29.904 resultados para panorama docente. Já para o período mais recente de 2012 a 2016 teve o destaque do número de 13.949 resultados para panorama docente.

As autoras Gatti e Barreto (2009) ao referenciarem a publicação do seu livro afirmaram que:

\begin{abstract}
Procura traçar um panorama sobre os docentes em exercício e as questões pendentes, examinar a legislação e suas oscilações e complementações conjunturais, as condições dos cursos de formação e seu alunado, os modelos especiais de formação para atender à exigência de sua elevação para o nível superior, a formação continuada de professores. Busca ainda abordar questões relativas à carreira e ao salário docentes. 0 intuito é tentar levar a reflexão sobre a docência e a formação para seu exercício a um plano mais amplo e abrangente, na busca de superação de casuísmos. (GATTI; BARRETTO, 2009, p.13).
\end{abstract}

As múltiplas facetas que compõem a docência favorecem estabelecer a perspectiva de um panorama que é volátil e que compreende os diversos aspectos da complexidade do docente. Nesta mesma lógica, os autores chilenos (ASMUSSEN e; CORCIONE, 2016) especificam que as relações docentes também estão perpassadas pelas interações relacionadas com o envolvimento com outras pessoas do processo de ensino-aprendizagem 
desde os seus estudantes, as famílias dos estudantes e comunidade escolar como um todo nos aspectos relacionados aos níveis: socioeconômico, ao capital cultural, psicológico e emocional.

\section{CONSIDERAÇÕES}

O trabalho docente é permeado por aspectos variados que trazem marcas desde da pessoa singular do professor até características semelhantes que se estabelecem a partir da prática profissional. Com o trabalho docente não é possível falar numa identidade ou até num perfil para seu trabalho pela dinamicidade e complexidade do trabalho em si, neste sentido o termo panorama buscou contemplar esta lógica mutante.

Existe no Brasil uma gama de diferenciações de trabalho docente, que vão além do nível de atuação profissional, da formação destes professores e, sobretudo, das interações realizadas no cotidiano da profissão. Falar de trabalho docente apesar de trazer em mente o profissional da educação, comprometido com o processo de ensino e aprendizagem carrega também nesta perspectiva a complexidade do trabalho, que se transforma e que se altera substancialmente de forma contínua, como numa metáfora de uma célula viva que ao interagir-se transforma a si própria.

\section{REFERÊNCIAS}

ASMUSSEN, Pablo Cornejo; CORCIONE, Andrés Cabezas. Educar desde las emociones: panorama docente en la educación chilena. Revista Científica de Ciencias de la Salud, v. 9, n.2, p. 79-86, 2016. Disponível em:<

https://revistas.upeu.edu.pe/index.php/rc_salud/article/view/234/234>. Acesso em: 24 mar. 2017.

BONELLI, Maria da Gloria. Docência do Direito: fragmentação institucional, gênero e interseccionalidade. Cadernos de Pesquisa, v.47, n.163, p.94-120, jan./mar. 2017.

CAMPOS, Regina. Identidade profissional. In: FIDALGO, Fernando; MACHADO, Lucília. (Ed.). Dicionário da Educação Profissional. Belo Horizonte: Núcleo de Estudos sobre Trabalho e 
Educação, FaE/UFMG, 2000.

CANGUILHEM, Georges. Meio e normas do homem no trabalho. Proposições, v.12, n.2-3, p.35-36, jul./nov. 2001.

CANGUILHEM, Georges. O normal e o patológico. Tradução de Maria Tereza Redig de Carvalho Barrocas e Luiz Octávio Ferreira Leite. 4.ed. Rio de Janeiro: Florence Universitária, 2002.

COORDENAÇÃO DE APERFEIÇOAMENTO DE PESSOAL DE NÍVEL SUPERIOR. Ministério da Educação. Catalogo de teses e dissertações. Brasília: MEC, 2006. Disponível em: <http://bancodeteses.capes.gov.br/banco-teses/\#!/>. Acesso em: 12 mar. 2017.

COSME, Ariana; TRINDADE, Rui Eduardo. A atividade curricular e pedagógica dos professores como fonte de tensões e dilemas profissionais: contributo para uma interpelação sobre a profissão docente. Revista Brasileira de Educação, v. 22, n. 69, abr./jun. 2017.

GATTI, Bernardete A. Reconhecimento social e as políticas de carreira docente na educação básica. Cadernos de Pesquisa, v. 42, n. 145, p. 88-111, 2012. Disponível em: <http://www.scielo.br/pdf/cp/v42n145/07.pdf>. Acesso em: 12 set. 2013.

GATTI, Bernadete Angelina; BARRETO, Elba Siqueira de Sá. Professores do Brasil: impasses e desafios. Brasília: UNESCO, 2009.

HALL, Stuart. A Identidade Cultural na Pós-Modernidade. Tradução de Tomaz Tadeu da Silva; Guacira Lopes Louro. Rio de Janeiro: DP\&A, 2001.

MACHADO, Lucília. Perfil amplo de qualificação profissional. In: FIDALGO, Fernando; MACHADO, Lucília. (Ed.). Dicionário da educação profissional. Belo Horizonte: Núcleo de Estudos sobre Trabalho e Educação, FaE/UFMG, 2000.

OLIVEIRA, M. R. N.; BURNIER, S. Perfil das licenciaturas nos institutos federais de educação, ciência e tecnologia. In: CUNHA, D. M. et al. (Org.).

Formação/profissionalização de professores e formação profissional e tecnológica: fundamentos e reflexões contemporâneas. Belo Horizonte: Editora PUC Minas, 2013.

OLIVEIRA, M. A. M; CUNHA, Daisy; SOARES, Juliana. Formação de professores para a educação profissional: um estudo histórico e crítico. In: SCARELI, Giovana (Org.) Educação, culturas, políticas e práticas educacionais e suas relações com a pesquisa. Porto Alegre: Sulina, 2015.

PASCHOALINO, Jussara Bueno de Queiroz. O professor desencantado: matizes do trabalho docente. Belo Horizonte: Armazém de Idéias, 2009. 
PASCHOALINO, Jussara B. de Queiroz; ALTOÉ, Adaílton. Presenteísmo e trabalho docente. Curitiba: CRV, 2015.

PASCHOALINO, Jussara Bueno de Queiroz. Desafios da gestão escolar. Belo Horizonte: Studium Eficaz, 2017.

RAMOS, Marise Nogueira. A educação profissional pela pedagogia das competências: para além da superfície dos documentos oficiais. Educação e Sociedade, v 23, n. 80, p.401-422, set. 2002.

SCHWARTZ, Yves. Trabalho e valor. Tempo Social; Revista de Sociologia, São Paulo, v. 8, n.2, p.147-158, 1996. Disponível em: < http://www.scielo.br/pdf/ts/v8n2/0103-2070-ts08-02-0147.pdf>. Acesso em: 27 ago. 2018.

SOCA, Ricardo. A fascinante história de palavras e fascinantes novas histórias de palavras. Disponível em: <http://www.elcastellano.org/palabra. php?id=954>. Acesso em: 10 set. 2014.

TARDIF Maurice; LESSARD, Claude. 0 trabalho docente: elementos para uma teoria da docência como profissão de interações humanas. Petrópolis, RJ: Vozes, 2005. 